\title{
ẢNH HƯỞNG CỦA MẬT ĐỘ ƯƠNG LÊN SINH TRƯỎNG VÀ TỶ LÊ SỐNG CỦA CÁ TÂMM NGA (ACIPENSER GUELDENSTAEDTII BRANDT, 1833) GIAI ĐOẠN CÁ BỘT LÊN CÁ HƯƠNG
}

\author{
Nguyễn Viết Thùy ${ }^{1 *}$, Trần Văn Dũng ${ }^{2}$ \\ ${ }^{1}$ Viện Nghiên cứu Nuôi trồng Thủy sản III, Việt Nam \\ ${ }^{2}$ Viện Nuôi trồng Thủy sản-Trường Đại học Nha Trang, Việt Nam \\ Email: thuy0032000@yahoo.com
}

Ngày nhận bài: 1-8-2013

\begin{abstract}
TÓM TĂT: Trong nghiên cưu này, 3 mật độ uơng 1.000, 2.000 và $3.000 \mathrm{con} / \mathrm{m}^{2}$ được thử nghiệm nhằm tìm ra mật độ thich hợp cho uơng cá tầm Nga giai đoạn cá bột lên cá hưong. Kết quả nghiên cưu cho thấy, tốc độ tăng trương tuyệt đối của cá ương ở mật độ $1.000 \mathrm{con} / \mathrm{m}^{2}$ (0,21 g/con/ngày) cao hon so vói cá ưong ở mật độ 2.000 (0,17 g/con/ngày) và $3.000 \mathrm{con} / \mathrm{m}^{2}$ (0,15 g/con/ngày; $p<0,05)$. Tốc độ tăng trưởng tương đối của cá uơng ở mật độ $1.000 \mathrm{con} / \mathrm{m}^{2} \mathrm{cao}$ hơn so với cá uơng ở mật độ $3.000 \mathrm{con} / \mathrm{m}^{2}(56,2$ so với 46,6\%; $p<0,05)$ nhưng không khác biệt với mật độ $2.000 \mathrm{con} / \mathrm{m}^{2}(51,1 \%$; $p>0,05)$. Tỷ lệ sống của cá uơng ở mật độ 1.000 và $2.000 \mathrm{con} / \mathrm{m}^{2}$ $(83,3$ và $76,3 \%)$ cao hơn so với mật độ $3.000 \mathrm{con} / \mathrm{m}^{2}$ (60,3\%). Tù nghiên cứu này có thể nhận thấy, mật độ thích hợp cho uoong cá tầm Nga giai đoạn cá bột lên cá hương là dưới $2.000 \mathrm{con} / \mathrm{m}^{2}$ nhằm đảm bảo tốc độ tăng truơong, tỷ lệ sống cũng nhu tận dụng tốt thể tích uoong nuôi.
\end{abstract}

Tù khóa: Acipenser gueldenstaedtii, cá tầm Nga, mật độ uơng, tốc độ tăng truơong, tỷ lệ sống.

\section{ĐặT VẤN ĐỀ}

Cá tầm Nga là loài cá sụn, có giá trị kinh tế rất cao, thịt thơm ngon và được nhiều người ưa chuộng. Trứng cá tầm Nga (caviar) có giá rất cao trên thị trường thế giới (trên $5.000 \mathrm{USD} / \mathrm{kg}$ ) trong khi đó thịt của chúng chỉ có giá khoảng 20 USD/kg [3]. Cá tầm Nga phân bố tự nhiên ở các vùng ôn đới, nhất là các vùng xứ lạnh như Nga, Bulgari, Ukraina, Rumani, ... Cá tầm Nga có khả năng thích ứng tốt với sự thay đổi của nhiệt độ $\left(2-30^{\circ} \mathrm{C}\right)$ và độ mặn $[4,9]$. Cá tầm Nga đã được di nhập và nuôi ở nhiều quốc gia ở châu Âu, châu Mỹ và châu Á trong đó có Việt Nam [5]. Việc khai thác quá mức và ngăn sông, đắp đập xây thủy điện ở những vùng cá tầm phân bố tự nhiên đã làm suy giảm sản lượng khai thác của loài cá này $[3,9]$.
Ở Việt Nam, ngay từ khi nhập về năm 2005, cá tầm Nga đã nhanh chóng thích ứng tốt với điều kiện nuôi ở các thủy vực nước ngọt, lạnh thuộc Tây Bắc và Tây Nguyên [1]. Trong vài năm trở lại đây, nghề nuôi cá nước lạnh ở nước ta, với hai đối tượng chủ lực là cá tầm và cá hồi vân, phát triển hết sức mạnh mẽ cả về diện tích và sản lượng. Sự phát triển của của nghề nuôi cá tầm đã đưa Việt Nam nằm trong nhóm 10 nước sản xuất cá tầm lớn nhất thế giới [1]. Việc phát triển nghề nuôi cá nước lạnh có ý nghĩa rất lớn đối với sự phát triển kinh tế, xã hội ở các vùng núi cao giúp tận dụng hiệu quả các vùng nước lạnh, vốn không thích hợp cho nuôi các đối tượng cá nước ngọt nhiệt đới truyền thống, để nuôi các đối tượng có giá trị kinh tế rất cao như cá tầm và cá hồi vân. 
Tuy nhiên, nghề nuôi cá tầm Nga hiện cũng đang gặp rất nhiều khó khăn do phải nhập khẩu trực tiếp trứng, cá giống và thức ăn từ các nước như Mỹ, Phần Lan và Trung Quốc [1]. Điều này làm gia tăng rủi ro và chi phí trong quá trình sản xuất. Kết quả ương giống cá nói chung và cá tầm Nga nói riêng phụ thuộc vào nhiều yếu tố như chất lượng con giống, thức ăn, các yếu tố môi trường, mật độ ương, thiết bị ương ... [8, 12]. Trong đó, mật độ ương là một trong những yếu tố quan trọng ảnh hưởng đến hiệu quả kinh tế và kỹ thuật. Việc gia tăng mật độ ương giúp tận dụng tốt diện tích nuôi, gia tăng hiệu quả kinh tế, tuy nhiên lại đi kèm với nhiều rủi ro như làm giảm tốc độ tăng trưởng, tỷ lệ sống, khả năng kháng bệnh của cá, đặc biệt trong điều kiện ương nuôi với mật độ cao [7, 10, 12, 13]. Một số nghiên cứu về ảnh hưởng của mật độ ương lên sinh trưởng và tỷ lệ sống của cá tầm cho thấy, tùy giai đoạn ương mà mật độ thích hợp từ $1.000-5.000 \mathrm{con} / \mathrm{m}^{2}$ đối với giai đoạn cá bột lên cá hương và 200 $800 \mathrm{con} / \mathrm{m}^{3}$ giai đoạn cá hương lên cá giống. Tuy nhiên, ở các nước nhiệt đới như Việt Nam, nhiệt độ thấp có được là do chênh lệch áp suất theo độ cao, do đó, mật độ ương cá nước lạnh thường thấp hơn so với vùng ôn đới do giới hạn hòa tan của oxy vào nước theo độ cao. Cho đến nay, ở nước ta vẫn chưa có nghiên cứu nào về ảnh hưởng của mật độ ương lên sinh trưởng và tỷ lệ sống của cá tầm Nga giai đoạn cá bột lên cá hương. Nghiên cứu này được thực hiện nhằm xác định mật độ ương phù hợp góp phần nâng cao tốc độ tăng trưởng, tỷ lệ sông và hiệu quả ương cá tầm Nga giai đoạn cá bột lên cá hương trong điều kiện Lâm Đồng và các tỉnh vùng Tây Nguyên.

\section{VẬT LIỆU VÀ PHƯƠNG PHÁP}

\section{Vật liệu và phương pháp bố trí thí nghiệm}

Nghiên cứu được thực hiện tại Trung tâm nghiên cứu Cá nước lạnh Tây Nguyên (Lâm Đồng) từ tháng 2 - 10 năm 2011 trên đối tượng cá tầm Nga (Acipenser gueldenstaedtii Brandt, 1833).

Nguồn cá thí nghiệm: cá bột đưa vào thí nghiệm được ấp nở tại Lâm Đồng từ nguồn trứng đã thụ tinh nhập từ Nga. Sau 7 - 9 ngày, cá bột tiêu hóa hết lượng noãn hoàng, tiến hành bố trí vào các bể thí nghiệm. Cá đưa vào thí nghiệm là những cá thể khỏe mạnh, vận động linh hoạt và đồng đều về kích cỡ.

Phương pháp bố trí thí nghiệm: nghiên cứu ảnh hưởng của mật độ ương lên tăng trưởng và tỷ lệ sống của cá được tiến hành từ giai đoạn cá bột $(0,40 \pm 0,09 \mathrm{~g} / \mathrm{con})$ lên cá hương $(3,5$ $4,5 \mathrm{~g} / \mathrm{con})$ với 3 mật độ $1.000,2.000$ và $3.000 \mathrm{con} / \mathrm{m}^{2}$. Thời gian ương là 30 ngày. Thí nghiệm được thực hiện với 3 lần lặp cùng thời điểm.

Bể thí nghiệm: cá được ương trong các bể composite hình tròn, diện tích $3 \mathrm{~m}^{2}$, chiều cao $0,6 \mathrm{~m}$, mực nước $0,2-0,3 \mathrm{~m}$. Bể ương được cấp nước chảy liên tục bằng máy bơm nước với lưu lượng từ $10-15 \mathrm{~L} /$ phút. Nguồn nước được bơm từ suối chảy qua lớp mút mịn trước khi cấp vào bể ương. Toàn bộ hệ thống bể ương được đặt trong nhà có mái che nhằm ổn định các yếu tố môi trường.

Thức ăn và chế độ cho ăn: Giai đoạn 5 - 10 ngày đầu, cá được cho ăn ấu trùng Artemia, sau đó, bổ sung trùn chỉ (Tubifex sp.) và thức ăn công nghiệp từ ngày thứ 20 trở đi (thức ăn tôm Lansy, hàm lượng protein trên $50 \%$, kích cỡ hạt $1,5 \mu \mathrm{m})$. Cá được cho ăn với tỷ lệ $8-16 \%$ khối lượng thân/ngày, chia làm 12 lần ăn/ngày sau đó giảm xuống 8 lần ăn/ngày.

Quản lý các yếu tố môi trường: các yếu tố môi trường như nhiệt độ nước, hàm lượng oxy hòa tan (đo 1 ngày/lần), $\mathrm{pH}$, hàm lượng $\mathrm{N}-\mathrm{NH}_{3}$ và $\mathrm{H}_{2} \mathrm{~S}$ (đo 1 tuần/lần) được kiểm tra định kỳ bằng các dụng cụ (nhiệt kế, test $\mathrm{oxy}, \mathrm{pH}, \mathrm{N}$ $\mathrm{NH}_{3}$ và $\mathrm{H}_{2} \mathrm{~S}$ ) và duy trì trong phạm vi thích hợp với sự tăng trưởng và phát triển của cá. Hàng ngày, bể ương được tiến hành siphon, vệ sinh, loại bỏ thức ăn thừa, chất thải và cá chết nhằm ngăn ngừa tác nhân gây bệnh.

\section{Phương pháp thu thập và xử lý số liệu}

Tốc độ tăng trưởng tuyệt đối và tương đối của cá được xác định định kỳ (7 ngày/lần) bằng cách thu ngẫu nhiên 30 con trong mỗi bể ương. Khối lượng cá được xác định bằng cân điện tử có độ chính xác $0,01 \mathrm{~g}$. Tỷ lệ sống của cá được xác định bằng cách đếm tất cả số lượng cá tại thời điểm kết thúc thí nghiệm chia cho sô lượng cá ban đầu. 
Tốc độ tăng trưởng tuyệt đối AGR ( $\mathrm{g} /$ con/ngày) và tương đối RGR (\%):

$$
\begin{gathered}
A G R=\frac{W 2-W 1}{t 2-t 1}(\mathrm{~g} / \text { con/ngày }) \\
R G R=\frac{W 2-W 1}{W 1} \times 100 \%
\end{gathered}
$$

Trong đó: W1, W2 - Khối lượng cá ở thời điểm $\mathrm{t} 1, \mathrm{t} 2(\mathrm{~g})$;

$\mathrm{t} 1, \mathrm{t} 2$ - Thời điểm cân cá lần trước và sau (ngày).

Tỷ lệ sống: Tỷ lệ sống $(\%)=($ Số cá khi kết thúc thí nghiệm / Số cá ban đầu) × 100\%

Các số liệu được xử lý bằng phần mềm SPSS 16.0. Sử dung phương pháp phân tích phương sai một yếu tố (oneway - ANOVA) và phép kiểm định Duncan để so sánh sự khác biệt có ý nghĩa thống kê $(p<0,05)$ về tốc độ tăng trưởng tuyệt đối, tương đối và tỷ lệ sống của cá giữa các nghiệm thức thí nghiệm. Toàn bộ số liệu được trình bày dưới dạng giá trị trung bình (TB) \pm sai số chuấn $(\mathrm{SE})$.

\section{KẾT QUẢ VÀ THẢO LUẬN}

\section{Diễn biến các yếu tố môi trường}

Nhìn chung, các yếu tố môi trường như nhiệt độ nước $\left(16,4 \pm 1,2^{\circ} \mathrm{C}\right)$, hàm lượng oxy

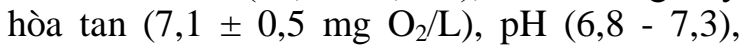
hàm lượng $\mathrm{N}_{-} \mathrm{NH}_{3}(<0,15 \mathrm{mg} / \mathrm{L})$ và $\mathrm{H}_{2} \mathrm{~S}(<$ $0,02 \mathrm{mg} / \mathrm{L}$ ) đều nằm trong phạm vi thích hợp cho sinh trưởng và phát triến của cá tầm $\mathrm{Nga}$ giai đoạn cá bột lên cá hương [4]. Do bể ương được đặt trong nhà, cấp nước chảy liên tục nên chất lượng môi trường rất thích hợp và ổn định trong suốt quá trình ương.

Ảnh hưởng của mật độ lên tốc độ tăng trưởng tuyệt đối của cá tầm Nga

Kết quả nghiên cứu cho thấy, mật độ ương có ảnh hưởng rõ rệt đến tốc độ tăng trưởng tuyệt đối (AGR) của cá tầm Nga giai đoạn cá bột lên cá hương với xu hướng chung là mật độ thấp hơn cho tốc độ tăng trưởng cao hơn. Sau 4 tuần ương, tốc độ tăng trưởng tuyệt đối của cá ương ở mật độ $1.000 \quad \mathrm{con} / \mathrm{m}^{2} \quad(0,21 \quad \pm$ $0,01 \mathrm{~g} / \mathrm{con} / \mathrm{ngày}$ ) cao hơn so với mật độ ương $2.000 \mathrm{con} / \mathrm{m}^{2}(0,17 \pm 0,01 \mathrm{~g} / \mathrm{con} /$ ngày $)$ và
$3.000 \mathrm{con} / \mathrm{m}^{2}(0,15 \pm 0,01 \mathrm{~g} / \mathrm{con} /$ ngày $)(\mathrm{p}<$ $0,05)$ (hình 1).

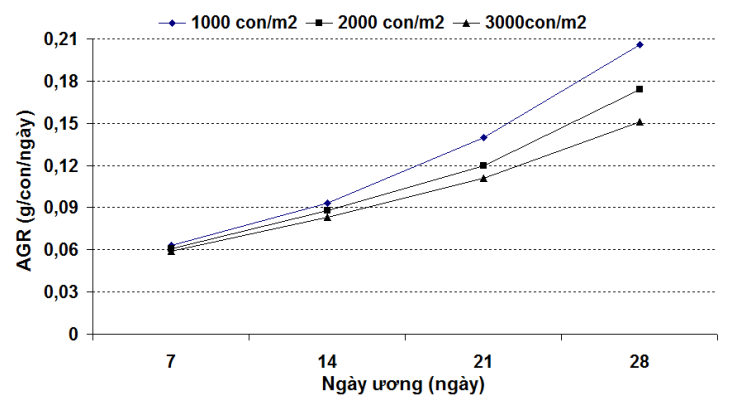

Hình 1. Ảnh hưởng của mật độ ương lên tốc độ tăng trưởng tuyệt đối của cá tầm Nga

Ảnh hưởng của mật độ ương lên tốc độ tăng trưởng tương đối của cá tầm Nga

Mật độ ương cũng ảnh hưởng đến tốc độ tăng trưởng tương đối (RGR) của cá tầm Nga. Cá được ương ở mật độ $1.000 \mathrm{con} / \mathrm{m}^{2}$ (57,2 \pm $1,3 \%$ ) đạt tốc độ tăng trưởng tương đối cao hơn so với mật độ ương $3.000 \mathrm{con} / \mathrm{m}^{2}(46,6 \pm 2,9 \%)$ $(\mathrm{p}<0,05)$. Tương tự, với tốc độ tăng trưởng tuyệt đối, không có sự khác biệt về tốc độ tăng trưởng tương đổi giữa cá được ương ở mật độ $2.000 \mathrm{con} / \mathrm{m}^{2}(51,1 \pm 1,5 \%)$ so với mật độ ương 1.000 và $3.000 \mathrm{con} / \mathrm{m}^{2}(\mathrm{p}<0,05)$ (hình 2$)$.

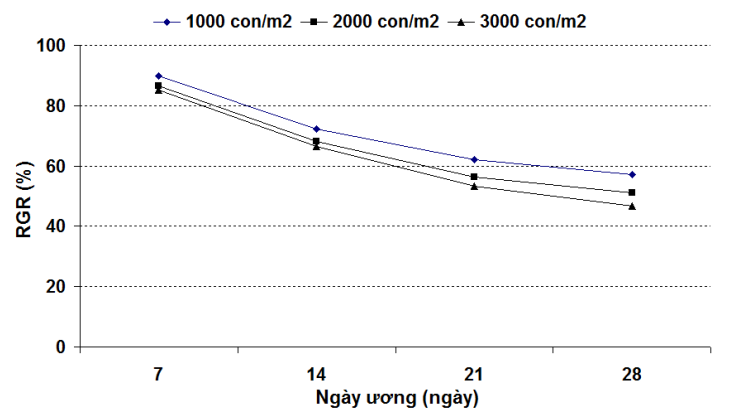

Hình 2. Ảnh hưởng của mật độ ương lên tốc độ tăng trưởng tương đối của cá tầm $\mathrm{Nga}$

\section{Ảnh hưởng của mật độ ương lên tỷ lệ sống của cá tầm Nga}

Mật độ ương cũng ảnh hưởng đáng kể đến tỷ lệ sống của cá tầm Nga giai đoạn cá bột lên cá hương. Cá được ương ở mật độ $1.000 \mathrm{con} / \mathrm{m}^{2}(83,3 \pm 5,5 \%)$ cho tỷ lệ sống cao hơn so với mật độ ương $2.000 \mathrm{con} / \mathrm{m}^{2}(78,3 \pm$ $6,0 \%)$ và $3.000 \mathrm{con} / \mathrm{m}^{2}(60,3 \pm 3,8 \%)(\mathrm{p}<$ 
0,05). Tuy nhiên, không có sự khác biệt về tỷ lệ sống giữa cá được ương ở mật độ 2.000 và $3.000 \mathrm{con} / \mathrm{m}^{2}$ ( $\left.\mathrm{p}>0,05\right)$ (hình 3$)$.

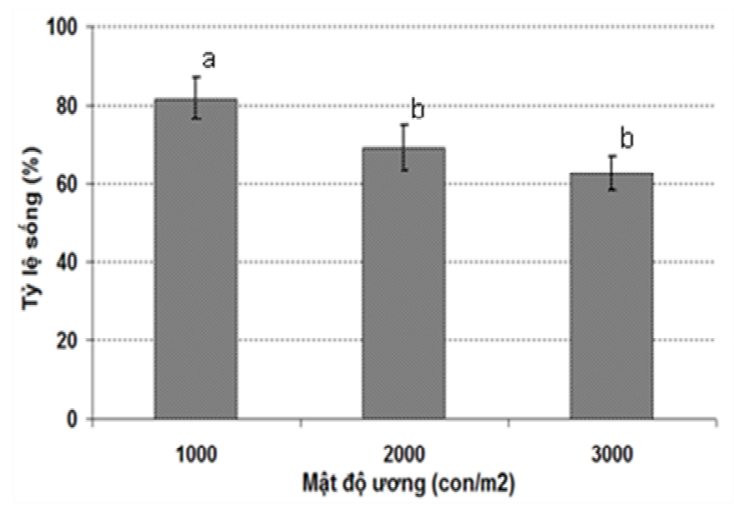

Hình 3. Ảnh hưởng của mật độ ương lên tỷ lệ sống của cá tầm $\mathrm{Nga}$

Các ký tụ (a, b, c khác nhau) trên hình thể hiện sụ khác biệt thống kê $(p<0,05)$

Nâng cao năng suất ương nuôi trên một đơn vị diện tích hay thể tích là một trong những điểm mấu chốt nâng cao hiệu quả của nghể nuôi trồng thủy sản và được quan tâm nghiên cứu bởi nhiều tác giả, trên nhiều đối tượng nuôi trong đó có cá tầm $[8,14]$. Việc gia tăng mật độ nuôi cho phép nâng cao sản lượng, tuy nhiên, điều này liên quan mật thiết đến nhiều vấn đề như thiêt kế hệ thống nuôi, chế độ cho ăn, quản lý môi trường và phòng trừ dịch bệnh [2]. Tác động tiêu cực của việc gia tăng mật độ nuôi có thể nhận thấy như bất thường về tập tính, sức khỏe và các hoạt động sinh lý của cá, ô nhiễm môi trường, từ đó, làm cá dễ bị stress, nhiễm bệnh, tăng trưởng chậm và gia tăng tỷ lệ chết $[6,7,10]$.

Trong nghiên cứu hiện tại, ở giai đoạn cá bột lên cá hương, cá tầm Nga được ương ở mật độ $1.000 \mathrm{con} / \mathrm{m}^{2}$ cho tốc độ tăng trưởng tuyệt đối, tương đối, khối lượng sau cao hơn so với mật độ ương $3.000 \mathrm{con} / \mathrm{m}^{2}$. Kết quả này là phù hợp với kết quả nghiên cứu của nhiều tác giả trước đó trên một số loài cá tầm Acipencer spp. khi cho rằng gia tăng mật độ nuôi làm giảm tôc độ tăng trưởng của cá $[7,8,10,13,14]$. Tốc độ tăng trưởng chậm ở các lô thí nghiệm ương với mật độ cao hơn có thể do sự cạnh tranh thức ăn, không gian sống chật hẹp, cá bị stress, hàm lượng ôxy hòa tan thấp, suy giảm chất lượng nước ... Ương nuôi cá tâm Acipenser schrenckii với các mật độ 0,$3 ; 0,75$ và $1,78 \mathrm{~kg} / \mathrm{m}^{2}$ [7] hay 0,$322 ; 0,665 ; 1,347$ và $2,469 \mathrm{~kg} / \mathrm{m}^{2}$ [14] đều nhận thấy, gia tăng mật độ nuôi làm giảm tốc độ tăng trưởng, giảm hiệu quả sử dụng thức ăn, hàm lượng một số loại hormone tăng trưởng. Tuy nhiên, Zhuang và đồng nghiệp lại nhận thấy hệ số chuyển đổi thức ăn và sinh khối cá đạt được gia tăng cùng mật độ nuôi [14]. Tương tự, nghiên cứu của Shi và đồng nghiệp cũng trên loài cá này cho thấy, mật độ ương $\left(0,525 ; 1,171\right.$ và $\left.2,138 \mathrm{~kg} / \mathrm{m}^{2}\right)$ có ảnh hưởng rõ rệt đến tốc tăng trưởng của cá với xu hướng chung là mật độ càng cao tốc độ tăng trưởng càng thấp [10]. Ngoài ra, gia tăng mật độ nuôi còn làm giảm khả năng tiêu hóa thức ăn và tỷ lệ ăn mồi ở cá. Xu hướng tương tự cũng được báo cáo trên loài cá tầm này giai đoạn giống $(8,7 \mathrm{~cm})$ ương với các mật độ $120,240,360$, 480 và $600 \mathrm{con} / \mathrm{m}^{3}$ [13]. Các quan sát trong quá trình ương và so sánh với các nghiên cứu khác cũng cho thấy, cá tầm hay cá hồi vân ở Lâm Đồng hay các vùng cao nguyên nước ta nói chung khó ương ở mật độ cao (3.000 $5.000 \mathrm{con} / \mathrm{m}^{2}$ ) do sự chênh lệch về độ cao với các vùng nuôi khác. Trong điều kiện Lầm Đồng, nhiệt độ thấp tạo ra là do vị trí nẳm ở trên cao hơn $1.500 \mathrm{~m}$ so với mực nước biển, trong khi, càng lên cao, áp suất không khí giảm làm giảm khả năng hòa tan của ôxy vào nước. Hơn nữa, ôxy lại chính là yếu tố giới hạn năng suất cá nuôi, đặc biệt là đối với những loài cá ưa nước chảy. Chính vì vậy, mật độ ương dưới 2.000 $\mathrm{con} / \mathrm{m}^{2}$ được xác định là thích hợp cho ương cá tầm Nga từ giai đoạn cá bột lên cá hương.

Tương tự tốc độ tăng trưởng, mật độ ương có ảnh hưởng lớn đến tỷ lệ sông của cá nói chung và cá tầm nói riêng $[11,13]$. Trong nghiên cứu hiện tại, cá tầm Nga ương ở mật độ 1.000 và $2.000 \mathrm{con} / \mathrm{m}^{2}$ cho tỷ lệ sống cao hơn so với mật độ $3.000 \mathrm{con} / \mathrm{m}^{2}$. Kết quả này cũng tương tự nghiên cứu của Yang và đồng nghiệp trên loài Acipenser schrenckii và $A$. gueldenstaedtii [13]. Nhiều nghiên cứu cũng chỉ rõ, ương nuôi cá ở mật độ cao làm gia tăng nguy cơ cạnh tranh thức ăn, không gian sống, ô nhiê̂m môi trường, cá dễ bị stress và nhiễm bệnh $[6,7]$, do đó, làm giảm tỷ lệ sống trong quá trình ương $[10,13,14]$. 
Ảnh hưởng của mật độ ương lên sinh trưởng ...

\section{KẾT LUẬN VÀ KIẾN NGH!}

\section{Kết luận}

Tốc độ tăng trưởng tuyệt đối và tỷ lệ sống của cá ương ở mật $1.000 \mathrm{con} / \mathrm{m}^{2}$ cao hơn so với cá ương ở mật độ 2.000 và $3.000 \mathrm{con} / \mathrm{m}^{2}(0,21$ so với 0,17 và $0,15 \mathrm{~g} / \mathrm{con} / \mathrm{ngày} ; 83,3$ so với 78,3 và $60,3 \%$ ). Tốc độ tăng trưởng tương đối của cá ương ở mật độ $1.000 \mathrm{con} / \mathrm{m}^{2}$ cao hơn so với cá ương ở mật độ $3.000 \mathrm{con} / \mathrm{m}^{2}$ nhưng không khác biệt với mật độ $2.000 \mathrm{con} / \mathrm{m}^{2}(57,2$ và $51,1 \%$ so với $46,6 \%$ ).

\section{Kiến nghị}

Cần nghiên cứu sâu hơn về ảnh hưởng của mật độ ương lên khả năng chịu sốc, hiệu quả sử dụng thức ăn, chất lượng môi trường nước, tỷ lệ phân đàn của cá tầm Nga giai đoạn cá bột lên cá giống.

\section{TÀI LIÊUU THAM KHẢO}

1. Trần Đình Luân, 2012. Hiện trạng sản xuất giống và nuôi cá tầm ở Việt Nam. Tạp chí Thương mại Thủy sản, số 154. Tr. 85-89.

2. Boujard, T., L. Labbe, B. Auperin, 2002. Feeding behavior, energy expenditure and growth of rainbow trout in relation to stocking density and food accessibility. Aquaculture Research 33(15): 1,233-1,242.

3. Chebanov, M., Rosenthal, H., Gessner, J., Van Anrooy, R., Doukakis, P., Pourkazemi, M., Williot, P., 2011. Sturgeon hatchery practices and management for release. Guidelines FAO Fisheries and Aquaculture Technical Paper No 570. Ankara, FAO. 2011. 110 pp.

4. Doroshov, S. I., 1985. Biology and culture of sturgeon. Acipenseriformes. In: Recent advances in aquaculture. Muir, J.F., Roberts, R., Ed. Westview Press., 2: 251-274.

5. FAO, 2006. Cultured Aquatic Species Information Programme. Cultured Aquaculture Species - Siberian Sturgeon In: FAO Fisheries and Aquaculture Department. Rome.

6. Hasanalipour, A., Eagderi, S., Poorbagher, S., Bahmani, M., 2013. Effects of stocking density on blood cortisol, glucose and cholesterol levels of immature Siberian Sturgeon (Acipenser baerii Brandt, 1869). Turkish Journal of Fisheries and Aquatic Sciences 13: 1-6.

7. Li, D., Liu, J., Xie, C., 2012. Effect of stocking density on growth and serum concentrations of thyroid hormones and cortisol in Amur sturgeon, Acipenser schrenckii. Fish Physiology and Biochemistry, 38 (2): 511-520.

8. Ronayi, A., 1997. Effects of stocking density and feeding frequencies on growth, feed utilization and size structure in juvenile Siberian sturgeon. Halaszat, 2: 91-96.

9. Ruban, G. I., 2005. The Siberian Sturgeon Acipenser baerii Brandt. Species structure and Ecology. Rosental H. K. (ed). World Sturgeon Conservation Society. Special Publication Series. Special Publication No 1. Norderstedt. Germany. 203 p.

10. Shi, X., Li, D., Zhuang, P., Zhang, X., Nie, $F$., 2006. Effects of rearing density on juvenile Acipenser schrenckii digestibility, feeding rate and growth. Journal of applied ecology, 17 (8): 1,517-1,520.

11. Tao, S. X., 2006. The stress-influences of rearing densities on juvenile amur sturgeon, Acipenser schrenckii. The Master thesis of Science. Huazhong Agricultural University. $58 \mathrm{pp}$.

12. Yan, T., 2007. The study on physiological and biochemical responds of Acipenser schrenckii to the stresses of ambient salinity, $\mathrm{pH}$ and capture. Master thesis of Science. East China Normal University. $96 \mathrm{pp}$.

13. Yang, D. G., Zhu, Y. J., Luo, I. P., Zhao,J. H., Chen, J. W., 2011. Effect of stocking density on growth performance of juvenile Amur Sturgeon (Acipenser schrenckii). Journal of Applied Ichthyology, 27(2): 541-544.

14. Zhuang, P., Li, D., Wang, M., Zhang, Z., Zhang, L., Zhang, T., 2002. Effect of stocking density on growth of juvenile Acipenser schrenckii. Journal of Applied Ecology, 13(6): 735-738. 


\title{
EFFECT OF DENSITY ON GROWTH AND SURVIVAL RATE OF RUSSIAN STURGEON (ACIPENSER GUELDENSTAEDTII BRANDT, 1833) FROM FRY TO FINGERLING STAGE
}

\author{
Nguyen Viet Thuy ${ }^{1}$, Tran Van Dung ${ }^{2}$
}

${ }^{1}$ Research Institute for Aquaculture No. 3, Viet Nam

${ }^{2}$ Institute of Aquaculture-Nha Trang University, Viet Nam

\begin{abstract}
In this study, three densities of 1,000, 2,000 and 3,000 ind. $/ \mathrm{m}^{2}$ were experimented in order to identify an appropriate density for rearing Russian sturgeon from the stage of fry to fingerling. Results showed that the absolute growth rate of the fish reared at the density of $1,000 \mathrm{ind} . / \mathrm{m}^{2}(0.21 \mathrm{~g} / \mathrm{ind} . /$ day $)$ was higher than those of the densities of 2,000 (0.17 g/ind./day) and 3,000 ind. $/ \mathrm{m}^{2}$ (0.15 g/ind./day) ( $\left.p<0.05\right)$. Relative growth rate of the fish reared at the density of $1,000 \mathrm{ind} . / \mathrm{m}^{2}$ was higher than that of the density of $3,000 \mathrm{ind} / \mathrm{m}^{2}(57,2 \%$ as opposed to $46.6 \%$; $p<$ $0.05)$ but not significantly different from that of the density of 2,000 ind. $/ \mathrm{m}^{2}(46.6 \% ; p>0.05)$. The survival rates of the fish reared at the densities of 1,000 and $2,000 \mathrm{ind} . / \mathrm{m}^{2}(83.3$ and $76.3 \%)$ were higher than those of the density of 3,000 ind. $/ \mathrm{m}^{2}(60.3 \%, p<0.05)$. From the results of this study, it can be suggested that the suitable density for rearing the Russian sturgeon from the stage of fry to fingerling should be less than 2,000 ind. $/ \mathrm{m}^{2}$ in order to optimize the growth, survival rate and tank rearing squares.
\end{abstract}

Keywords: Acipenser gueldenstaedtii, growth rate, rearing density, Russian sturgeon, survival rate. 